\title{
A novel angiomatoid epithelioid sarcoma cell line, Asra-EPS, forming tumors with large cysts containing hemorrhagic fluid in vivo
}

\author{
Yoshinori Imura ${ }^{1}$, Norifumi Naka ${ }^{1,2^{*}}$, Hidetatsu Outani ${ }^{1}$, Hirohiko Yasui ${ }^{1}$, Satoshi Takenaka ${ }^{1}$, Ken-ichiro Hamada ${ }^{1}$, \\ Ritsuro Ozaki ${ }^{1}$, Mitsunori Kaya ${ }^{3}$, Ken-ichi Yoshida ${ }^{4}$, Eiichi Morii ${ }^{4}$, Akira Myoui ${ }^{1}$ and Hideki Yoshikawa ${ }^{1}$
}

\begin{abstract}
Background: Whereas we can use several human epithelioid sarcoma (ES) cell lines for basic and preclinical research, an angiomatoid ES cell line has not been reported to date. We have treated a case of an angiomatoid ES developing in the right upper extremity of a 67-year-old man.

Methods: An angiomatoid ES cell line, Asra-EPS was newly established and characterized for its morphology, growth rate and chromosomal analysis. Tumorigenicity of Asra-EPS cells was also analyzed in athymic nude mice.

Results: Asra-EPS cells were round, polygonal or spindle-shaped with an abundant cytoplasm and have been maintained continuously in vitro for over 150 passages during more than 15 months. These cells secreted cancer antigen 125 (CA 125), interleukin-6 (IL-6) and vascular endothelial growth factor (VEGF) into the culture medium. Asra-EPS cells were tumorigenic when implanted in nude mice with tumors reaching a volume of $1000 \mathrm{~mm}^{3}$ at around 50 days. Histological features of tumors formed in mice were essentially the same as those of the original tumor, exhibiting a multinodular proliferation of eosinophilic epithelioid and spindle-shaped cells with prominent areas of hemorrhage and blood-filled cystic spaces strikingly corresponding to the potential of hemorrhagic cyst formation in the original tumor. They showed immunopositive staining for cytokeratins (AE1/AE3 and CAM5.2), epithelial membrane antigen (EMA), vimentin, CD31, CD34 and CA 125, but negative for integrase interactor 1 (INI-1) and factor VIII-related antigen.
\end{abstract}

Conclusions: The established cell line represents a biologically relevant new tool to investigate the molecular pathology of human angiomatoid ES and to evaluate the efficacy of novel therapeutics both in vitro and in vivo.

Keywords: Epithelioid sarcoma, Asra-EPS, VEGF, CA 125, INI-1, Cystogenesis

\section{Background}

Epithelioid sarcoma (ES) was first described in 1970 by Enzinger as a distinct soft tissue tumor with mixed epithelial and mesenchymal phenotype, but the origin and true nature of ES remain controversial [1]. In general, ES is a relatively rare sarcoma and accounts for less than $1 \%$ of all soft tissue sarcoma [2]. The clinical course of ES is usually characterized by local recurrence and the potential for metastatic spread mostly to lymph nodes

\footnotetext{
* Correspondence: nnaka@ort.med.osaka-u.ac.jp

'Department of Orthopaedic Surgery, Osaka University Graduate School of Medicine, 2-2 Yamadaoka, Suita, Osaka 565-0871, Japan

${ }^{2}$ Department of Biology, Osaka Medical Center of Cancer and Cardiovascular Diseases, 1-3-3 Nakamichi, Higashinari-ku, Osaka 537-8511, Japan Full list of author information is available at the end of the article
}

and lung, but effective chemotherapy has not been established [3,4]. Two main clinicopathologic types of ES are recognized. The classic type manifests clinically as a painless, slow-growing nodule arising within the dermis or subcutis or, less commonly, in deep fascial or tenosynovial tissue [4]. Usually, it occurs in young adults at the flexor surface of the fingers, hand, wrist, and forearm, followed by knee and lower leg. On the other hand, the less common type, also known as the proximal type or large cell/rhabdoid ES, occurs predominantly in middle-aged or older adults in axial proximal locations such as pelvis, mediastinum and trunk, as deep infiltrative masses [5]. Additionally, other lesser common variants have been described, including the angiomatoid 
variant and the fibroma-like variant [6,7]. Until now, some case reports of angiomatoid ES, which distinctively features cyst formation and hemorrhage within tumor nodules, have been described [8,9]. To date, a small number of ES cell lines have successfully been established [10-21], but there is no cell line from angiomatoid ES reported (Table 1). We herein present a case of angiomatoid ES arising in a 67-year-old man and establish an angiomatoid ES cell line from this patient. In this study, we describe the characteristics of a newly established angiomatoid ES cell line, Asra-EPS, both in vitro and in vivo.

\section{Methods}

\section{Case report}

The patient was a 67-year-old Japanese man. Six months before presentation to our institute, he noted a painful soft tissue mass in his right elbow and was referred to the primary hospital. He had no history of trauma or other illness including hemorrhagic diathesis. The tumor was diagnosed as a spontaneous hematoma since magnetic resonance imaging (MRI) revealed fluid-fluid level collection. It had gradually increased in size over a 5month period. Pain was activity related initially and became more constant later in the course. At the first presentation to our hospital, he had a huge tumor measuring $10 \times 7 \times 13 \mathrm{~cm}$ in his right upper extremity, with intolerable pain, numbness, and nearly complete palsy at the area of median and radial nerve in his hand. Blood analyses revealed the data to be within normal limits except for a marked elevation of C-reactive protein (CRP) and cancer antigen 125 (CA 125). The serum CRP and CA 125 levels were $7.52 \mathrm{mg} / \mathrm{dl}$ (normal: $\leq 0.2 \mathrm{mg} / \mathrm{dl}$ ) and $769 \mathrm{U} / \mathrm{ml}$ (normal: $\leq 35 \mathrm{U} / \mathrm{ml}$ ), respectively. Reexamined MRI showed large multinodular cystic tumors with satellite lesions in his right arm, infiltrating major neurovascular structures (Figure 1A, B, C, D). Computed tomography $(\mathrm{CT})$ of the chest revealed no metastatic lesions in the lungs. Percutaneous needle biopsy was performed and microscopic examination of the specimen exhibited a nodular growth pattern with central necrosis, composed of compact sheets of epithelioid and spindle-shaped cells. In parts, prominent areas of hemorrhage and foci with blood-filled cystic spaces were observed. A tentative histological diagnosis of epithelioid angiosarcoma or angiomatoid ES was made. A right above-elbow amputation was performed because of high-grade malignancy and tumor infiltration into major neurovascular structures. Macroscopically, large cyst filled with coagulated blood occupied most part of the amputated arm. Microscopic examination of the specimen revealed the same as percutaneous needle biopsy (Figure 2A, B). Immunohistochemistry showed positivity of tumor cells for cytokeratins (AE1/AE3 and CAM5.2) (Figure 2C, D), epithelial membrane antigen (EMA) (Figure 2E), vimentin (Figure 2F), CD31 (Figure 2G), CD34 (Figure 2H) and CA 125 (Figure 2I) whereas integrase interactor 1 (INI-1) and factor VIII-related antigen were negative (Figure 2J, K), confirming the histological diagnosis as angiomatoid ES based mainly on the CA 125 and INI-1 immunoreactivity. Positive rate of Ki-67 was approximately $50 \%$ (Figure $2 \mathrm{~L}$ ). Radiotherapy composed of $60 \mathrm{~Gy} / 30 \mathrm{fr}$ was done between the right shoulder including axilla and the stump of arm postoperatively in 5 weeks. Adjuvant chemotherapy was not administered due to age based limitations. At 21 days after the operation, the serum CRP and CA 125 levels decreased to $0.03 \mathrm{mg} / \mathrm{dl}$ and $53 \mathrm{U} / \mathrm{ml}$, respectively. Four months later, concomitant with re-elevation of the serum CRP and CA 125 levels, left axillary lymph node metastasis and

Table 1 Clinical and cytogenetic findings in epithelioid sarcoma cell lines which have been established until now

\begin{tabular}{|c|c|c|c|c|c|c|}
\hline Cell line (year) & Age/sex ${ }^{1}$ & Primary location & Doubling time $^{2}$ & Tumorigenicity $^{3}$ & CA $125^{4}$ & INI-1 $1^{5}$ \\
\hline RM-HS1 (1987) & $37 / M$ & Left foot & N.A & N.A & N.A & N.A \\
\hline HX 165c (1988) & $28 / M$ & Penis & $38 \mathrm{~h}$ & $N$ & N.A & N.A \\
\hline GRU-1 (1990) & $32 / M$ & Left buttock & $29 \mathrm{~h}$ & $\mathrm{~N}$ & N.A & N.A \\
\hline SARCCR2 (1993) & $33 / F$ & Knee & $28 \mathrm{~h}$ & N & N.A & N.A \\
\hline ES020488 (1993) & $26 / M$ & Left forearm & $60 \mathrm{~h}$ & $N$ & N.A & N.A \\
\hline VAESBJ (1995) & $41 / M$ & Epidural space & $32 \mathrm{~h}$ & $S$ & - & - \\
\hline ES-OMC-MN (1997) & $44 / F$ & Right leg & $68.5 \mathrm{~h}$ & - & N.A & N.A \\
\hline YCUS-5 (1999) & $3 / F$ & Neck & N.A & N.A & N.A & N.A \\
\hline SFT-8606 (2000) & $75 / \mathrm{M}$ & Left elbow & N.A & $S$ & + & N.A \\
\hline FU-EPS-1 (2005) & $21 / M$ & Right upper arm & $45 \mathrm{~h}$ & $S$ & + & N.A \\
\hline NEPS (2010) & $32 / \mathrm{M}$ & Forearm & N.A & $S$ & - & N.A \\
\hline Epi-544 (2011) & N.A/N.A & Foot & $48 \mathrm{~h}$ & $S$ & + & - \\
\hline Asra-EPS (2013) & $67 / M$ & Right elbow & $38 \mathrm{~h}$ & $\mathrm{~N}$ & + & - \\
\hline
\end{tabular}

${ }^{1} \mathrm{~F}$ female, $M$ male. ${ }^{12345} \mathrm{~N}$. $\mathrm{A}$ data not available. ${ }^{3} \mathrm{~N}$ nude mice, $S$ SCID mice. 

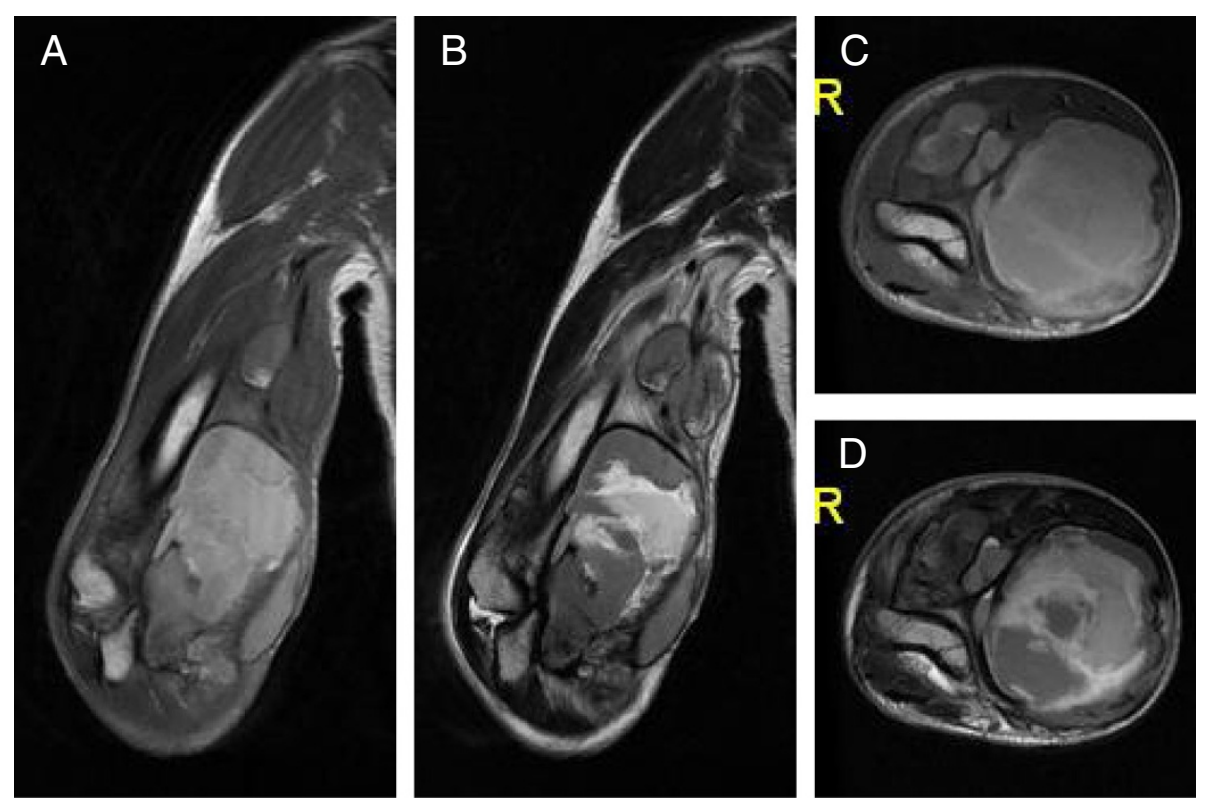

Figure $1 \mathrm{MRI}$ of the huge tumor in the right upper extremity of a 67-year-old man. (A) T1-weighted coronal image. (B) T2-weighted coronal image. (C) T1-weighted axial image. (D) T2-weighted axial image.
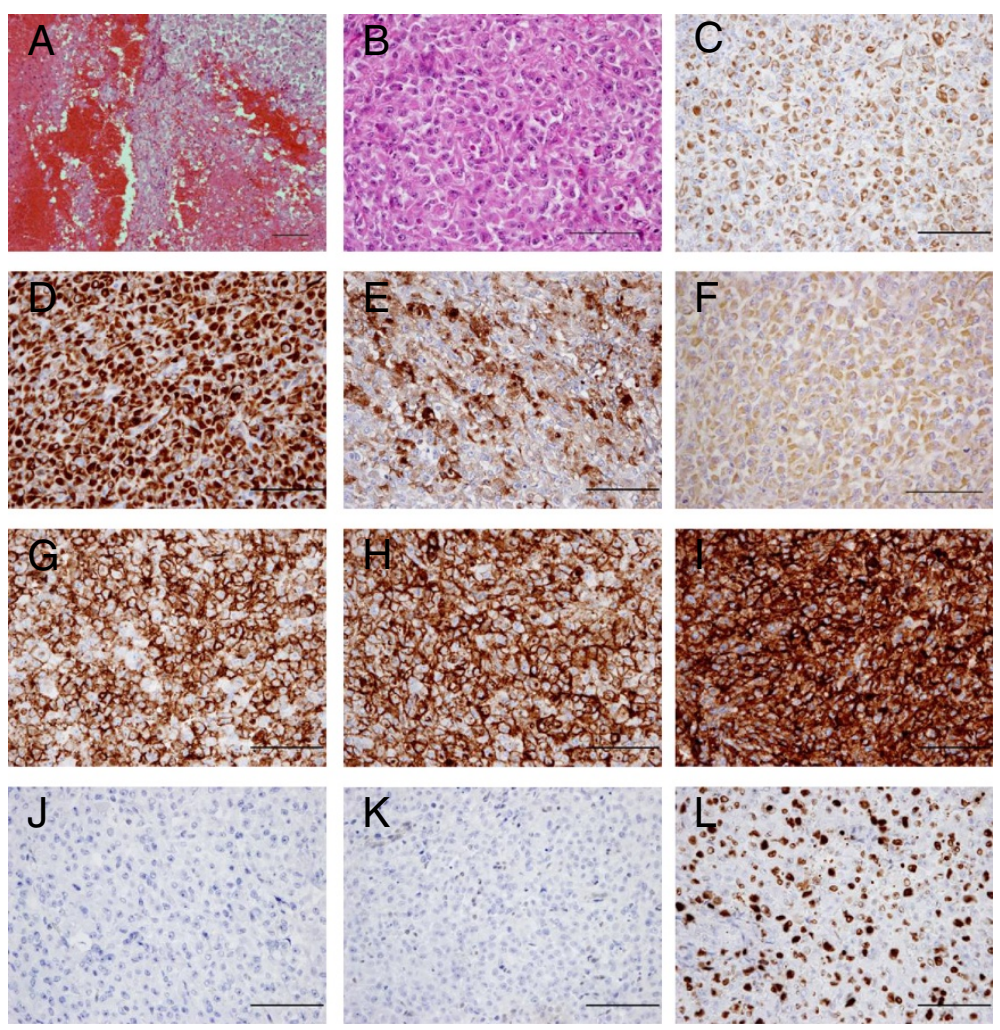

Figure 2 Microscopic features of the patient's original tumor. (A, B) Histological appearance of the original tumor. H\&E staining showed a multinodular proliferation of eosinophilic epithelioid and spindle-shaped cells with prominent areas of hemorrhage. (C-L) Immunohistochemical reactivity in the original tumor. Tumor cells were diffusely positive for AE1/AE3 (C), CAM5.2 (D), EMA (E), vimentin (F), CD31 (G), CD34 (H) and CA

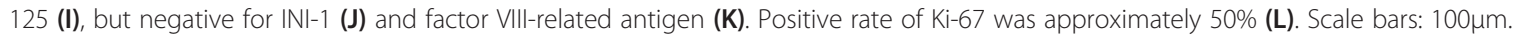


pulmonary lymphangitis sarcomatosa were found. Six months after the primary surgery, the patient died of respiratory insufficiency.

\section{Establishment of a new cell line from an angiomatoid ES} Tumor cells were isolated from surgically resected tissues with the patient's informed consent and under the guidelines of the Institutional Review Board for Clinical Research at Osaka University Hospital. The tumor tissues were minced and incubated with $1 \mathrm{mg} / \mathrm{ml}$ of collagenase (SigmaAldrich, St. Louis, MO, USA) for $1 \mathrm{~h}$ at $37^{\circ} \mathrm{C}$. Cell suspensions were passed through a $40-\mu \mathrm{m}$ nylon mesh (Becton Dickinson Falcon, Franklin Lakes, NJ, USA) and the tumor cells were cultured in Dulbecco's modified Eagle's medium (DMEM; GIBCO, Grand Island, NY, USA) with 10\% fetal bovine serum (FBS; Sigma). The adherent cells were maintained for over 15 months in culture, and passed more than 150 times. Attached cells exhibited spindle-shaped, epithelioid and polygonal morphology. This cell line was named Asra-EPS. Asra-EPS cells were cultured at $37^{\circ} \mathrm{C}$ with $95 \%$ air, $5 \% \mathrm{CO}_{2}$, and $100 \%$ humidity.

\section{Cell growth assay}

To determine the doubling time, $1 \times 10^{5}$ Asra-EPS cells were seeded into each well of 6-well plates (BD Falcon) with $2 \mathrm{ml}$ DMEM, supplemented with 10\% FBS. Three wells were trypsinized with $0.25 \%$ Trypsin plus EDTA (Invitrogen, Carlsbad, CA, USA) every $24 \mathrm{~h}$ and cell number for each well was counted with a hemocytometer for 8 days.

\section{Soft agar colony formation assay}

To determine the anchorage-independent cell growth ability, soft agar colony formation assay was performed. AsraEPS cells $\left(5 \times 10^{3}\right)$ were added to $0.5 \%$ SeaPlaque Agarose (Lonza, Basel, Switzerland) in $1 \mathrm{ml} \mathrm{DMEM}$ with $10 \%$ FBS over $0.6 \%$ agar in $2 \mathrm{ml}$ DMEM with $10 \%$ FBS in $35 \mathrm{~mm}$ plates (BD Falcon). For 3 weeks, plates were looked at every day to make sure they have not dried out and add growth medium to the plates when necessary.

\section{CA 125, interleukin-6 (IL-6) and vascular endothelial growth factor (VEGF) measurement in vitro}

Resuspension of $1 \times 10^{5}$ cells were planted in $2 \mathrm{ml}$ DMEM supplemented with $10 \%$ FBS on 6 -well plates. At 7 th day, culture medium was collected and centrifuged at $1200 \mathrm{~g}$ for $5 \mathrm{~min}$ to remove floating cells, and then the supernatant was stored at $-80^{\circ} \mathrm{C}$ until assay. The concentration of CA 125, IL- 6 and VEGF was measured by the chemiluminescent enzyme immunoassay (CLEIA) technique (SRL Inc., Tokyo, Japan).

\section{Nude mice xenografting}

Five-week-old athymic nude mice (BALB/c nu/nu; SLC, Shizuoka, Japan) were housed at the Institute of
Experimental Animal Sciences Osaka University Medical School, in accordance with guideline approved by the Institutional Animal Care and Use Committee of Osaka University Graduate School of Medicine. To determine the tumorigenicity of Asra-EPS cell line in vivo, $1 \times 10^{7}$ cells were injected subcutaneously into the left side of back. Mice were inspected twice a week and were sacrificed when the total tumor burden reached $2 \mathrm{~cm}^{3}$. Tumor size was measured with a caliper and tumor volume calculated by the formula $\left(\mathrm{a} \times \mathrm{b}^{2}\right) / 2$, with a being the longest diameter and $b$ the shortest diameter of the tumor. Tumors were then resected for immunohistochemical studies.

\section{Immunohistochemistry}

Immunohistochemical studies were performed to confirm whether the phenotype of the cultured cells matched with that of the original tumor cells. Specimens of the original tumor and of the tumors formed in nude mice were fixed in $10 \%$ neutral, buffered formalin, embedded in paraffin, sectioned at $4 \mu \mathrm{m}$ thickness, and stained with hematoxylin and eosin (H\&E). Paraffinembedded sections were deparaffinized and dehydrated. Antigens were retrieved at $95^{\circ} \mathrm{C}$ for $15 \mathrm{~min}$ in $10 \mathrm{mM}$ citrate buffer. After blocking of endogenous peroxidase activity for 10 min with methanol containing $3 \% \mathrm{H}_{2} \mathrm{O}_{2}$, the sections were reacted for $1 \mathrm{~h}$ with phosphatebuffered saline (PBS) containing $2 \%$ bovine serum albu$\min (\mathrm{BSA})$ at room temperature to prevent nonspecific binding. They were then incubated overnight with primary antibodies at $4^{\circ} \mathrm{C}$. Primary antibodies against AE1/ AE3 (1:100, Dako, Glostrup, Denmark), CAM5.2 (BD Biosciences, San Jose, CA, USA), EMA (1:100, Dako), vimentin (1:100, Abcam, Cambridge, UK), CD31 (1:50, Dako), CD34 (1:100, Leica Microsystems, Wetzlar, Germany), CA 125 (1:50, Dako), INI-1 (1:50, BD Biosciences), factor VIII-related antigen (1:50, Dako) and Ki67(1:75, Dako) were used. On the next day, the sections were incubated for $1 \mathrm{~h}$ with horseradish peroxidase (HRP)-conjugated secondary antibodies (1:500, BD Biosciences) and stained with 3,3'-diaminobenzidine tetrahydrochloride (DAB; Dako). The sections were finally counterstained with hematoxylin. As a negative control, staining was carried out in the absence of primary antibody.

\section{Western blotting}

Equal amounts of protein extracted from cultured cells were separated on 4-12\% Bis-Tris gels (Invitrogen) and transferred to PVDF membranes. The membranes were rinsed in Tris-buffered saline containing $0.1 \%$ Tween (TBS-T) and incubated in blocking buffer (5\% skim milk in TBS-T) at room temperature. The blocked membranes were incubated with anti-INI-1 antibody (1:1000) 
and anti-beta-actin antibody (1:1000, Santa Cruz Biotechnology, Inc., Santa Cruz, CA, USA) at $4^{\circ} \mathrm{C}$ overnight and washed with TBS-T 3 times for 5 min each time, followed by incubation with HRP-conjugated second antibodies (1:2000) at room temperature for $1 \mathrm{~h}$. After washing in TBS-T, the immunoreactive bands were visualized using enhanced chemiluminescence (ECL) (Perkin Elmer Life Sciences, Waltham, MA, USA).

\section{Chromosome analysis}

Metaphase chromosome spreads from Asra-EPS cells were prepared according to standard procedures. AsraEPS cells were treated with $20 \mu \mathrm{g} / \mathrm{ml}$ of colcemide overnight and harvested. After treatment of $0.075 \mathrm{M} \mathrm{KCl}$ for $20 \mathrm{~min}$ at $37^{\circ} \mathrm{C}$, cells were fixed 3 times with methanol and acetic acid (3:1) and fixed cells were spread on slides.

Multicolor fluorescence in situ hybridization (mFISH) was performed using commercially available mFISH kits (MetaSystems, Altlussheim, Germany) according to the manufacturer's protocol. Briefly metaphase spreads were hardened $70^{\circ} \mathrm{C}$ for $2 \mathrm{~h}$. After applying mFISH probes on the metaphase spreads, co-denaturation of target DNA with probe DNA was performed at $70^{\circ} \mathrm{C}$ for $5 \mathrm{~min}$, followed by $72 \mathrm{~h}$ incubation at $37^{\circ} \mathrm{C}$ to allow hybridization of the probes. The slides were then washed twice with $50 \%$ formamide $/ 2 \times$ standard saline citrate (SSC) solution for $20 \mathrm{~min}$ at $37^{\circ} \mathrm{C}, 2 \times \mathrm{SSC}$ for $10 \mathrm{~min}$ at room temperature and $1 \times \mathrm{SSC}$ for $10 \mathrm{~min}$. The slides were then counterstained with 4',6-diamidino-2phenylindole (DAPI) and mounted. Separate fluorochrome images were captured using a Leica DC 350FX cooled CCD camera (Leica) mounted on a Leica DMRA2 microscope using Leica CW4000 FISH software. The images were analyzed using Leica CW4000 karyo (Leica).

\section{Results}

\section{Cell morphology and colony formation in 2D and 3D} culture models

The cell line Asra-EPS has now been growing in standard 2D culture without interruption for over 15 months and has been passed at least 150 times. The line appeared to contain epithelial-like polygonal cells but, in addition, more mesenchymal-like spindle-shaped cells were apparent (Figure 3A). Both of these morphological phenotypes appeared to be stable with repeated passaging. Asra-EPS cells showed excellent growth without contact inhibition. The doubling time of Asra-EPS cells in logarithmic growth phase was approximately $38 \mathrm{~h}$ (Figure 3B). Asra-EPS cells could form colonies in soft agar (Figure 3C).

\section{Tumorigenicity of Asra-EPS cells in nude mice}

Fourteen days after injection of $1 \times 10^{7}$ Asra-EPS cells into the nude mice, tumor growth was evident in all 5
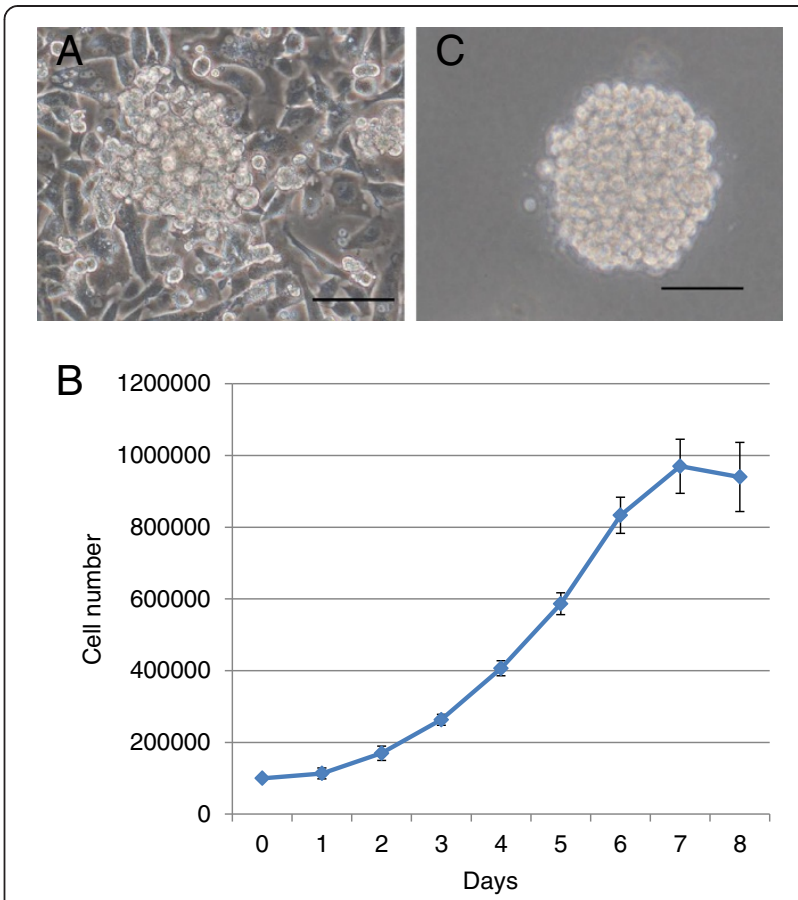

Figure 3 Characteristics of Asra-EPS cells in vitro. (A)

Morphology of Asra-EPS cells under 2D culture by phase-contrast microscopy. (B) Growth curve of Asra-EPS cells in vitro. Each point represents the mean value \pm standard deviation (SD) $(n=3)$. (C) Colony formation of Asra-EPS cells in soft agar. Scale bars: 100 $\mathrm{mm}$.

mice tested. The efficiency of tumor formation was extremely high. These tumors were serially transplantable in further mice as a stable xenograft line. The tumors were then resected, digested, and plated into dishes. These replated cells showed similar morphological features to the original cells from the patient tumor tissues. Eight weeks after injection of Asra-EPS cells, the average of Asra-EPS tumor volume was $1514 \mathrm{~mm}^{3}$ (Figure 4A). Asra-EPS tumors formed in mice also exhibited blood-filled cyst formation within them as they grew largely, reflecting the clinical feature of the original tumor (Figure 4B).

\section{Morphologic characteristics of Asra-EPS tumors}

$H \& E$ staining of Asra-EPS xenograft tumors with cysts formation and a wide range of hemorrhage demonstrated histological appearances resembling the original tumor (Figure 5A, B, C). The immunohistochemical profiles of both tissues from the patient tumor tissues and from Asra-EPS tumors formed in mice were the same as previous studies on human angiomatoid ES tissues [8,9]. Asra-EPS tumors exhibited positive staining for AE1/ AE3 (Figure 5D), CAM5.2 (Figure 5E), EMA (Figure 5F), vimentin (Figure 5G), CD31 (Figure 5H), CD34 (Figure 5I) and CA 125 (Figure 5J), but negative staining for INI-1 (Figure 5K) and factor VIII-related antigen (Figure 5L). Positive rate of Ki-67 in xenografted tumor 

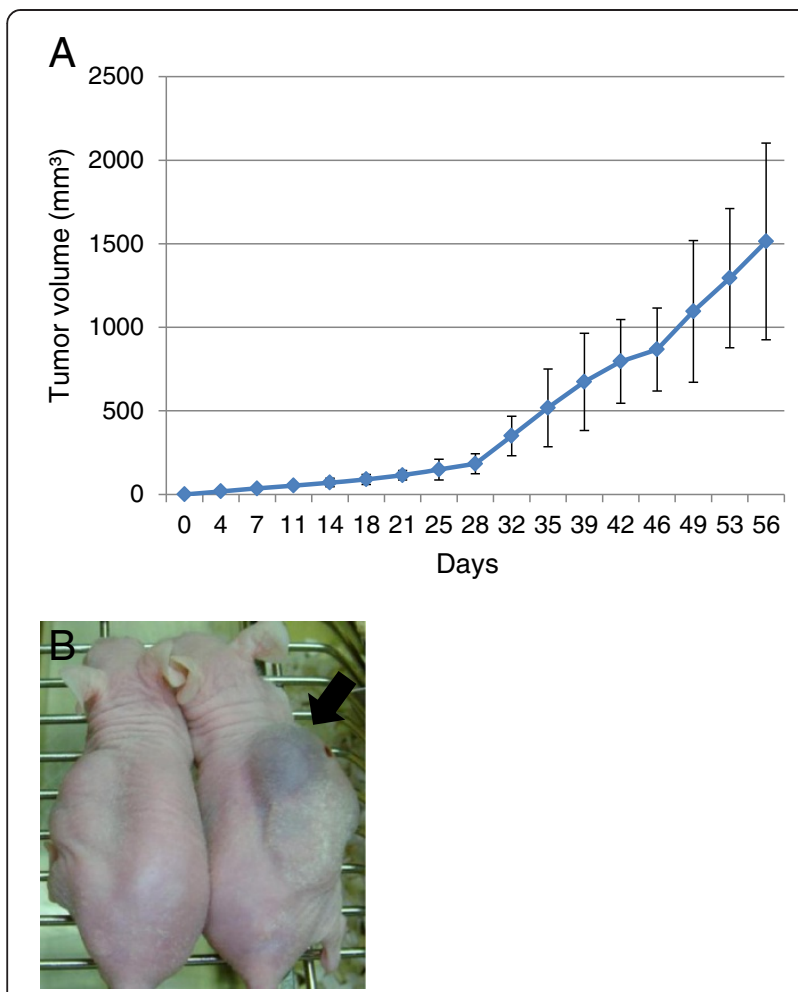

Figure 4 Characteristics of Asra-EPS tumors in vivo. (A) Growth curve of Asra-EPS tumors in nude mice. Each point represents the mean value $\pm S D(n=5)$. (B) Asra-EPS tumors with large cysts containing hemorrhagic fluid (black arrow).

was similar to that in the patient's tumor, approximately $50 \%$ (Figure 5M). In western blotting, no INI-1 expression was found in Asra-EPS cells, in contrast to the synovial sarcoma cell line Yamato-SS [22], which was used as a control (Figure 6).

\section{Secretion of CA 125, IL-6 and VEGF by Asra-EPS cells in vitro}

Amounts of CA 125, IL-6 and VEGF secreted into the culture medium of $1 \times 10^{5}$ Asra-EPS cells at 7th day culture were as follows: CA $125145 \mathrm{U} / \mathrm{ml}$; IL-6 7760 $\mathrm{pg} / \mathrm{ml}$; VEGF $957 \mathrm{pg} / \mathrm{ml}$. Asra-EPS cells produced CA 125, IL-6 and VEGF at high levels.

\section{Chromosome analysis}

In the chromosomal analysis, 50 metaphases were examined. The chromosome number of Asra-EPS cells at the 30th passage ranged from 45 to 133, with a mode of 90 . The karyotype of Asra-EPS showed near-tetraploidy with some chromosomal translocations and fragments (Figure 7). No recurrent chromosomal translocation was detected.

\section{Discussion}

Angiomatoid ES is less common variant of ES and its clinical features are still unknown [8,9]. Histologically, the tumor of angiomatoid ES is composed of epithelioid and spindle-shaped tumor cells exhibiting intracytoplasmic vacuoles reminiscent of intracytoplasmic vascular lumen formation [23]. The morphology of the tumor cells is similar to that seen in classical ES. Angiomatoid ES shows prominent areas of hemorrhage and foci with blood-filled cystic spaces within the tumor $[8,23]$. These features closely resemble those seen in malignant vascular tumors with epithelioid cytomorphology, including epithelioid angiosarcoma and epithelioid hemangioendothelioma [24].

In this study, we have succeeded in establishing an angiomatoid ES cell line, called Asra-EPS. To the best of our knowledge, this is the first report of establishing and characterizing an angiomatoid ES cell line. Asra-EPS cells exhibited the morphology of epithelial-like polygonal cells and mesenchymal-like spindle-shaped cells. Asra-EPS cell line had epithelial and mesenchymal features similar to those of the original tumor as revealed by immunohistochemistry, secreted CA 125, IL-6 and VEGF, did not express INI-1, and exhibited tumorigenicity in nude mice.

CA 125 is a tumor antigen forming the basis for a serum assay widely used to monitor the clinical status of patients with ovarian cancer $[25,26]$. Recently, elevated serum CA 125 was reported in two patients with ES [27]. Furthermore, a subsequent study by the same group indicated that 10 of their 11 cases of ES (classic type: 9 cases; proximal type: 1 case) showed strong immunoreactivity for CA 125 in the tumor cells [28]. Therefore, CA 125 could be considered to be a generally useful tumor marker for diagnosing ES and monitoring its clinical course. Nevertheless, it is unknown whether CA 125 would be a useful marker for diagnosing and monitoring the course of angiomatoid ES.

IL-6 is presently considered as the most important mediator of acute-phase protein synthesis in hepatocytes and cell culture experiments have suggested that IL-6 stimulates the synthesis of serum CRP [29-31]. A classical ES cell line, designated as ES-OMC-MN, was reported to produce IL-6, but not to be tumorigenic in nude mice [17]. In this study, we showed that Asra-EPS could constitutively produce CA 125 and IL-6. In this case, blood analyses showed significantly high levels of CA 125 and CRP in the sera before the surgery and rapid decline of those levels to the normal range after the surgery. At the recurrence, the serum levels of CA 125 and CRP were re-elevated. Taken together, these clinical findings indicated that the measurement of serum CA 125 and CRP could be recommended to diagnose angiomatoid ES and monitor its clinical course.

INI-1 is the protein product of the hSNF5/INII/ SMARCB1/BAF47 gene as a tumor suppressor gene located on $22 \mathrm{q} 11.2$ that is characteristically inactivated in malignant rhabdoid tumor (MRT) of infancy [32-35]. In 

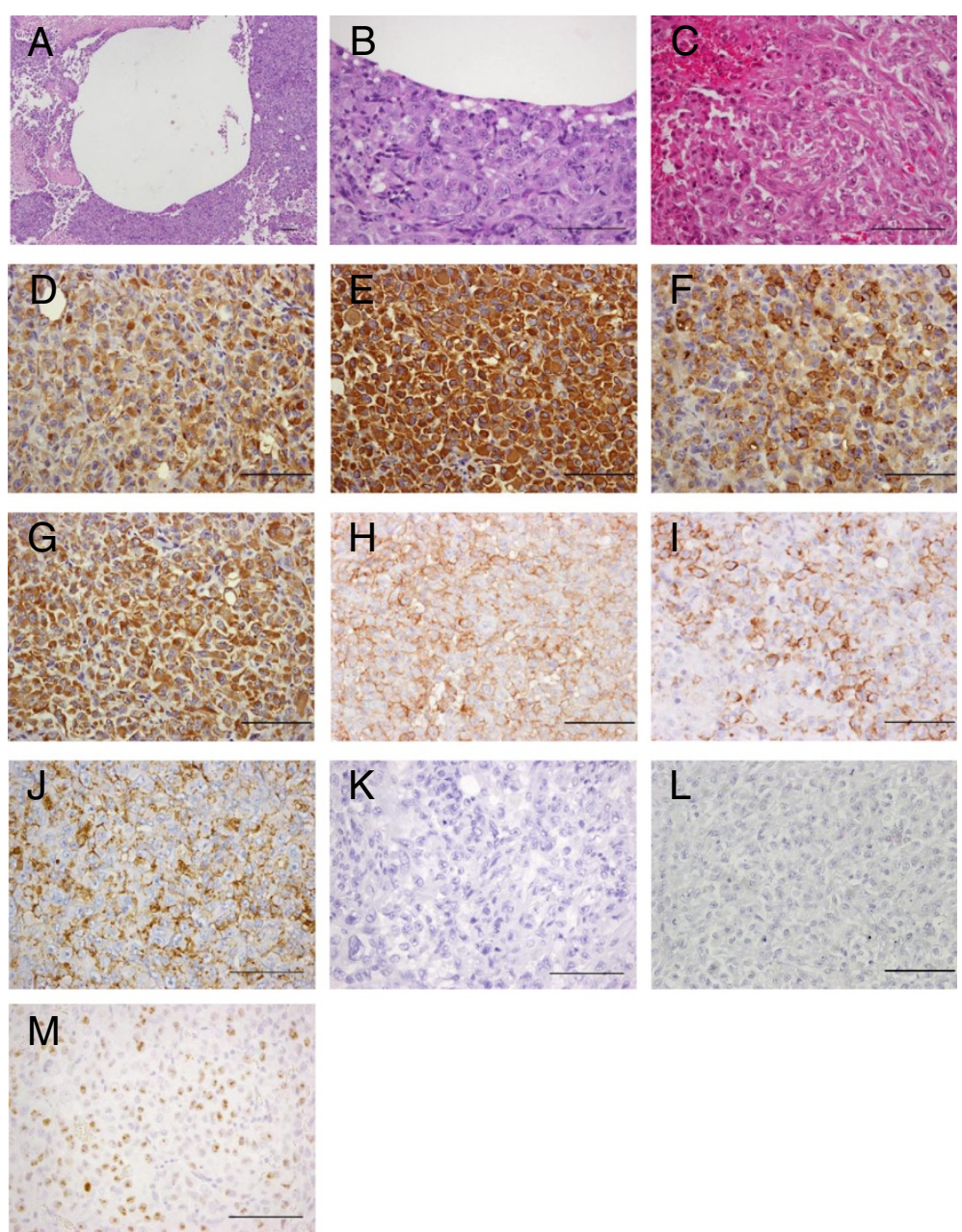

Figure 5 Microscopic features of Asra-EPS tumors formed in nude mice. (A-C) Histological appearance of Asra-EPS tumors (H\&E). Histological features of Asra-EPS tumors were almost the same as those of the original tumor. (D-M) Immunohistochemical reactivity in Asra-EPS tumors. Tumor cells were diffusely positive for AE1/AE3 (D), CAM5.2 (E), EMA (F), vimentin (G), CD31 (H), CD34 (I) and CA 125 (J), but negative

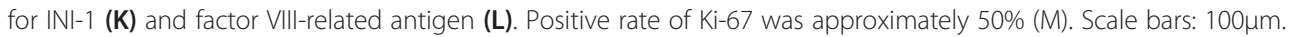

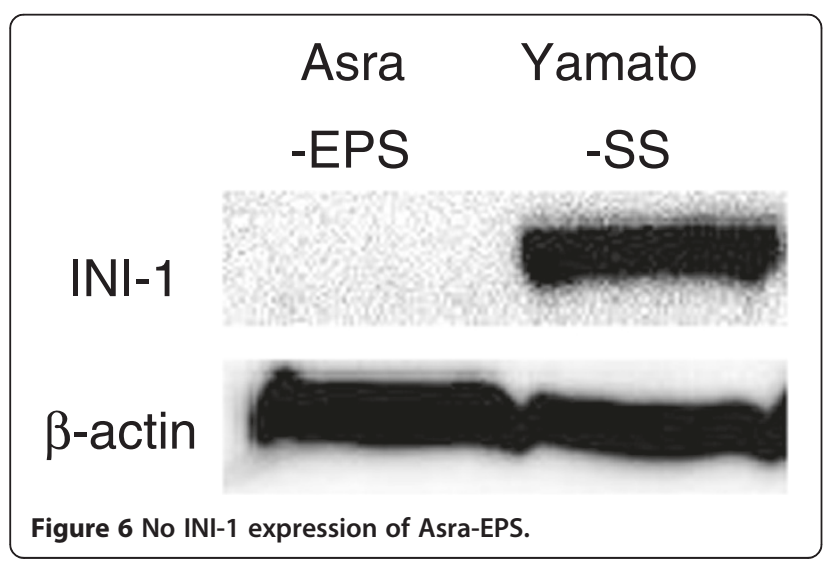

the previous study, most ES cases, both classical and proximal type, were reported to show complete loss of expression of INI-1 [36]. The present study demonstrated that INI-1 protein expression was also lost in the original tumor as well as our established angiomatoid ES cell line. INI-1 expression is retained in most of epithelioid angiosarcoma and epithelioid hemangioendothelioma. Thereby, the immunohistochemical profile of the angiomatoid ES was useful to differentiate them from malignant epithelioid vascular tumors with INI-1 and CA 125 immunoreactivity [21]. Asra-EPS cell line might provide us with a research material to elucidate the mechanism in the loss of INI-1 protein expression and its oncogenic functions in ES pathogenesis.

Surprisingly, Asra-EPS tumors formed in nude mice also showed prominent areas of hemorrhage and foci with blood-filled cystic spaces as they grew largely. Their 


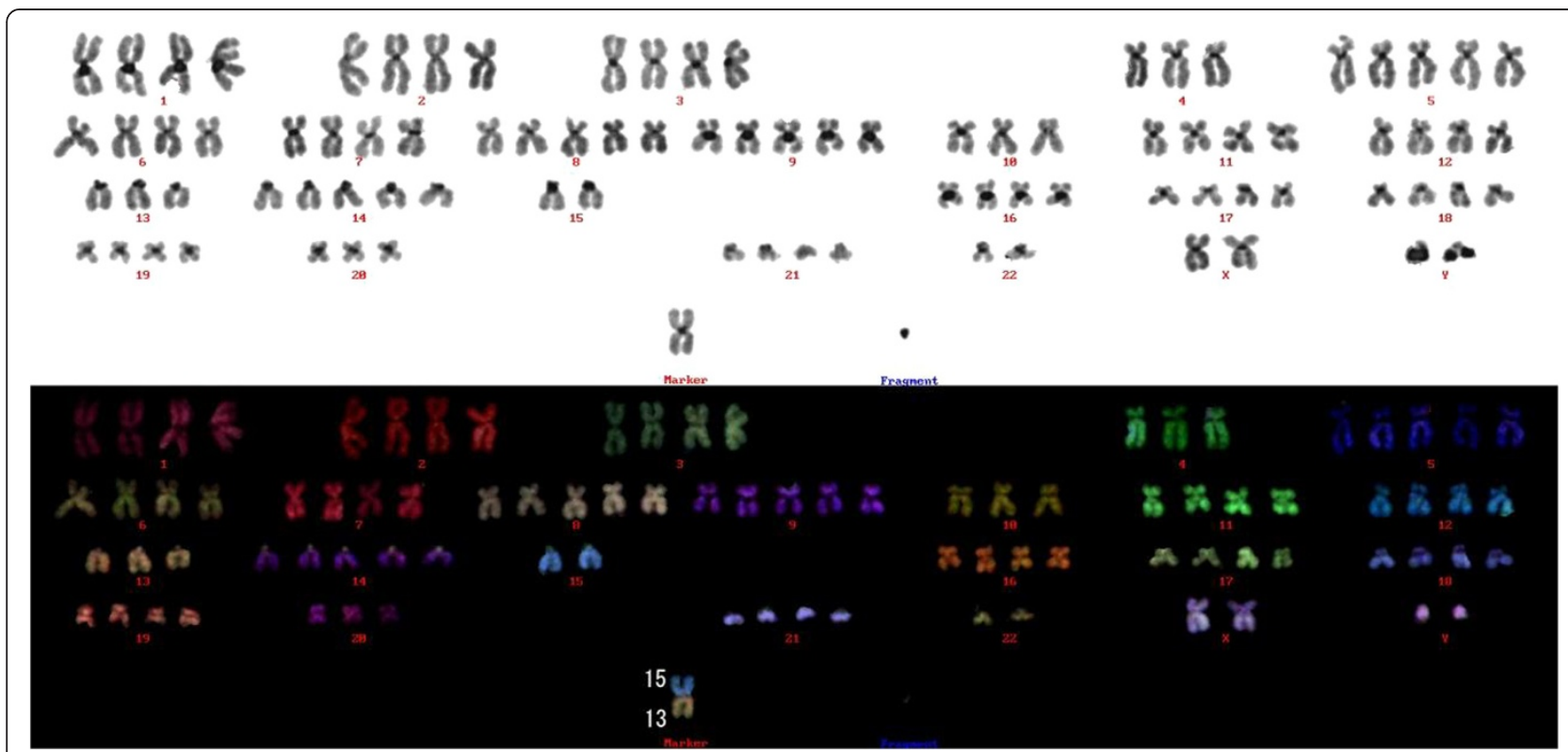

Figure 7 Representative karyotype of Asra-EPS at the 30th passage. It is $90, X X Y Y,-4,+5,+8,+9,-10,-13, t(13 ; 15),+14,-15,-15,-20,-22$, $-22,+1$ mar.

pathological appearance of cystogenesis in Asra-EPS closely resembles that of the original tumor. While OVCAR-3, one of ovarian cancer cell lines, has no potential to form the cysts itself [37], Duyndam and colleague reported that $\mathrm{VEGF}_{165}$-overexpression induced OVCAR-3 xenograft tumors to form the cysts containing hemorrhagic fluid and that $\mathrm{VEGF}_{165}$ might play a role in the cystogenesis [38]. To our knowledge, there is no report of cancer or sarcoma cell lines to spontaneously generate cysts within the xenograft tumors in vivo, except for the above described genetically engineered cancer cell line. Therefore, Asra-EPS is the first sarcoma cell line, with the potential to form tumors with large cysts containing hemorrhagic fluid in nude mice. Since Asra-EPS secreted a considerable amount of VEGF, molecular target drugs against VEGF might be effective to suppress the cystogenesis in Asra-EPS xenograft tumors. However, bevacizumab (Genentech/Roche, South San Francisco, CA, USA), a humanized monoclonal antibody to human VEGF, could not inhibit the formation of cysts in Asra-EPS tumors (data not shown). Collectively, these findings suggested that other growth factors than VEGF or cytokines might contribute to the cystogenesis in Asra-EPS tumors and further investigation is needed to clarify the molecular mechanism of cyst formation.

\section{Conclusions}

A newly established Asra-EPS cell line fully preserved the morphological and biochemical characteristics of the original tumor diagnosed as angiomatoid ES. Asra-EPS is an excellent tool for further investigation of the nature of angiomatoid ES, the mechanism in the formation of cyst, and potential therapies for patients with ES.

\section{Abbreviations}

BSA: Bvine serum albumin; CA 125: Cancer antigen 125;

CLEIA: Chemiluminescent enzyme immunoassay; CRP: C-reactive protein; CT: Computed tomography; DAB: 3,3'-diaminobenzidine tetrahydrochlorid; DAPI: 4'6-diamidino-2-phemylindole; DMEM: Dulbecco's modified Eagle's medium; ECL: Enhanced chemiluminescence; EMA: Epithelial membrane antigen; ES: Epithelioid sarcoma; FBS: Fetal bovine serum; H\&E: Hematoxylin and eosin; HRP: Horseradish peroxidase; IL-6: Interleukin-6; INI-1: Integrase interactor 1; $\mathrm{mFISH}$ : multicolor fluorescence in situ hybridization; MRI: Magnetic resonance imaging; MRT: Malignant rhabdoid tumor; PBS: Phosphate-buffered saline; SSC: Standard saline citrate; TBS-T: Trisbuffered saline containing $0.1 \%$ Tween; VEGF: Vascular endothelial growth factor.

Competing interests

The authors declare that they have no competing interests.

\section{Authors' contributions}

$\mathrm{YI}$ carried out the whole study and drafted the manuscript. YI and NN designed the study. NN revised the manuscript. NN, ST and RO operated the patient. NN, RO and MK treated the patient. HO, HY, ST, KH, AM and HY helped to draft the manuscript. KY and EM performed the pathological examination. All authors read and approved the final manuscript.

\section{Acknowledgements}

Written informed consent was obtained from the patient's next of kin for publication of this manuscript and accompanying images. A copy of the written consent is available for review by the Editor-in-Chief of this journal. We thank Mari Shinkawa and Asa Tada for their excellent technical assistance. This study was supported in part by grant-in -aid from the Ministry of Education, Science, and Culture, Japan (No. 24592233). 


\section{Author details}

${ }^{1}$ Department of Orthopaedic Surgery, Osaka University Graduate School of Medicine, 2-2 Yamadaoka, Suita, Osaka 565-0871, Japan. ²Department of Biology, Osaka Medical Center of Cancer and Cardiovascular Diseases, 1-3-3 Nakamichi, Higashinari-ku, Osaka 537-8511, Japan. ${ }^{3}$ Department of Orthopaedic Surgery, Chitose City Hospital, 2-1-1 Hokko, Chitose, Hokkaido 066-8550, Japan. ${ }^{4}$ Department of Pathology, Osaka University Graduate School of Medicine, 2-2 Yamadaoka, Suita, Osaka 565-0871, Japan.

Received: 23 April 2013 Accepted: 29 July 2013

Published: 1 August 2013

\section{References}

1. Enzinger FM: Epithelioid sarcoma. A sarcoma simulating a granuloma or carcinoma. Cancer 1970, 26:1029-1041.

2. de Visscher SA, van Ginkel RJ, Wobbes T, Veth RP, Ten Heuvel SE, Suurmeijer AJ, Hoekstra HJ: Epithelioid sarcoma: still an only surgically curable disease. Cancer 2006, 107:606-612.

3. Chase DR, Enzinger FM: Epithelioid sarcoma: diagnosis, prognostic indicators, and treatment. Am J Surg Pathol 1985, 9:241-263.

4. Halling AC, Wollen PC, Pritchard DJ, Vlasak R, Nascimento AG: Epithelioid sarcoma: a clinicopathologic review of 55 cases. Mayo Clin Med 2004, 71:636-642.

5. Guillou L, Wadden C, Coindre JM, Krausz T, Fletcher CD: "Proximal-type" epithelioid sarcoma: a distinctive aggressive neoplasm showing rhabdoid features, clinicopathologic, immunohistochemical, and ultrastructural study of a series. Am J Surg Pathol 1997, 21:130-146.

6. Von Hochstetter AR, Meyer VE, Grant JW, Honegger HP, Schreiber A: Epithelioid sarcoma mimicking angiosarcoma: the value of immunohistochemistry in the differential diagnosis. Virchows Arch A Pathol Anat Histopathol 1991, 418:271-278.

7. Mirra JM, Kessler S, Bhuta S, Eckardt J: The fibroma-like variant of epithelioid sarcoma. A fibrohistiocytic/myoid cell lesion often confused with benign and malignant spindle cell tumors. Cancer 1992, 69:1382-1395.

8. Kaddu S, Wolf I, Horn M, Kerl H: Epithelioid sarcoma with angiomatoid features: report of an unusual case arising in an elderly patient within a burn scar. J Cutan Pathol 2008, 35:324-328.

9. Brassesco MS, Valera ET, Castro-Gamero AM, Moreno DA, Silveira TP, Mori BM, Engel EE, Scrideli CA, Tone LG: Cytogenetic findings in an epithelioid sarcoma with angiomatoid features. A case report. Genet Mol Res 2009 8:1211-1217.

10. Reeves BR, Fisher C, Smith S, Courtenay VD, Robertson D: Ultrastructural, immunocytochemical and cytogenetic characterization of a human epithelioid sarcoma cell line (RM-HS1). J Natl Cancer Inst 1987, 78:7-18.

11. Kelland $L R$, Bingle $L$ : Radiosensitivity and characterization of a newly established cell line from an epithelioid sarcoma. Br J Cancer 1988, 58:322-325.

12. Gerharz CD, Moll R, Ramp U, Mellin W, Gabbert HE: Multidirectional differentiation in a newly established human epithelioid sarcoma cell line (GRU-1) with co-expression of vimentin, cytokeratin and neurofilament proteins. Int J Cancer 1990, 45:143-152.

13. Roche H, Julia AM, Jozan S, Muller C, Dastuque N, Arquier MA, Marques B, Laurent G, Canal P: Characterization and chemosensitivity of a human epithelioid sarcoma cell line (SARCCR 2). Int J Cancer 1993, 54:663-668.

14. Sonobe H, Furihata M, Iwata J, Oka T, Ohtsuki Y, Hamasato S, Fujimoto S: Morphological characterization of a new human epithelioid sarcoma cell line, ES020488, in vitro and in vivo. Virchows Arch B Cell Pathol 1993, 63:219-225.

15. Helson C, Melamed M, Braverman S, Traganos F, Preti R, Helson L: VA-ES-BJ: an epithelioid sarcoma cell line. Int J Oncol 1995, 7:51-56.

16. Iwasaki H, Ohjimi $Y$, Ishiguro M, Isayama T, Kaneko Y, Yoh S, Emoto G, Kikuchi M: Epithelioid sarcoma with an 18q aberration. Cancer Genet Cytogenet 1996, 91:46-52.

17. Kusakabe H, Sakatani S, Yonebayashi K, Kiyotake K: Establishment and characterization of an epithelioid sarcoma cell line with an autocrine response to interleukin-6. Arch Dermatol Res 1997, 289:224-233.

18. Goto H, Takahashi H, Funabiki T, Ikuta K, Sasaki H, Nagashima Y: Neura differentiation of a novel cell line, YCUS-5, established from proximaltype epithelioid sarcoma of a child. Med Pediatr Oncol 1999, 33:137-138.

19. Nishio J, Iwasaki H, Nabeshima K, Ishiguro M, Naumann S, Isayama T, Naito $M$, Kaneko $Y$, Kikuchi M, Bridge JA: Establishment of a new human epithelioid sarcoma cell line, FU-EPS-1: molecular cytogenetic characterization by use of spectral karyotyping and comparative genomic hybridization. Int J Oncol 2005, 27:361-369.
20. Hoshino M, Kawashima H, Ogose A, Kudo N, Ariizumi T, Hotta T, Umezu H, Hatano H, Morita T, Nishio J, Iwasaki H, Endo N: Serum CA 125 expression as a tumor marker for diagnosis and monitoring the clinical course of epithelioid sarcoma. J Cancer Res Clin Oncol 2010, 136:457-464.

21. Sakharpe A, Lahat G, Gulamhusein T, Liu P, Bolshakov S, Nguyen T, Zhang P, Belousov R, Young E, Xie X, Rao P, Hornick JL, Lazar AJ, Pollock RE, Lev D: Epithelioid sarcoma and unclassified sarcoma with epithelioid features: clinicopathological variables, molecular markers, and a new experimental model. Oncologist 2011, 16:512-522.

22. Naka N, Takenaka S, Araki N, Miwa N, Hashimoto N, Yoshioka K, Joyama S, Hamada K, Tsukamoto Y, Tomita Y, Ueda T, Yoshikawa H, Itoh K: Synovial sarcoma is stem cell malignancy. Stem Cells 2010, 28:1119-1131.

23. Miettinen $M$, Fanburg-Smith JC, Virolainen $M$, Shmookler BM, Fetsch JF: Epithelioid sarcoma. An immunohistochemical analysis of 112 classical and variant cases and a discussion of the differential diagnosis. Hum Pathol 1999, 30:934-942.

24. Von Hochstetter AR, Meyer VE, Grant JW, Honegger HP, Schreiber A Epithelioid sarcoma mimicking angiosarcoma. The value of immunohistochemistry in the differential diagnosis. Virchows Arch Pathol Anat Histopathol 1991, 418:271-278.

25. Yin BW, Dniatrian A, Lloyd KO: Ovarian cancer antigen CA125 is encoded by the MUC16 mucin gene. Int J Cancer 2002, 98:737-740.

26. Bast RC Jr, Badgwell D, Lu Z, Marquez R, Rosen D, Liu J, Baggerly KA, Atkinson EN, Skates S, Zhang Z, Lokshin A, Menon U, Jacobs I, Lu K: New tumor markers: CA125 and beyond. Int J Gynecol Cancer 2005, 15:274-281.

27. Kato $H$, Hatori $M$, Watanabe $M$, Kokubun S: Epithelioid sarcoma with elevated serum CA125: report of two cases. Jpn J Clin Oncol 2003, 33:141-144.

28. Kato H, Hatori M, Kokubun S, Watanabe M, Smith RA, Hotta T, Ogose A, Morita T, Murakami T, Aiba S: CA125 expression in epithelioid sarcoma. Jpn J Clin Oncol 2004, 34:149-154.

29. Shine B, de Beer FC, Pepys MB: Solid phase radioimmunoassays for human C-reactive protein. Clin Chim Acta 1981, 117:13-23.

30. de Beer FC, Hind CR, Fox KM, Allan RM, Maseri A, Pepys MB: Measurement of serum $C$-reactive protein concentration in myocardial ischaemia and infarction. Br Hearl J 1982, 47:239-243.

31. Castell JV, Gomez-Lechon ML, David M, Andus T, Geiger T, Trullenque R, Fabra R, Heinrich PC: Interleukin- 6 is the major regulator of acute phase protein synthesis in adult human hepatocytes. FEBS Lett 1989, 242:237-239.

32. Versteege I, Sevenet $N$, Lange J, Rousseau-Merck MF, Ambros P, Handgretinger R, Aurias A, Delattre O: Truncating mutations of hSNF5/INI1 in aggressive paediatric cancer. Nature 1998, 394:203-206.

33. Bourdeaut F, Freneaux P, Thuille B, Lellouch-Tubiana A, Nicolas A, Pierron G, Sainte-Rose C, Bergeron C, Bouvier R, Rialland X, Laurence V, Michon J, Sastre-Garau X, Delattre O: hSNF5/INI1-deficient tumours and rhabdoid tumours are convergent but not fully overlapping entities. J Pathol 2007, 211:323-330.

34. Kalpana GV, Marmon S, Wang W, Crabtree GR, Goff SP: Binding and stimulation of HIV-1 integrase by a human homolog of yeast transcription factor SNF5. Science 1994, 266:2002-2006.

35. Ae K, Kobayashi N, Sakuma R, Ogata T, Kuroda H, Kawaguchi N, Shinomiya K, Kitamura Y: Chromatin remodeling factor encoded by ini1 G1 arrest and apotosis in ini1-deficient cells. Oncogene 2002, 21:3112-3120.

36. Hornick JL, Dal Cin P, Fletcher CD: Loss of INI1 expression is characteristic of both conventional and proximal-type epithelioid sarcoma. Am J Surg Pathol 2009, 33:542-550

37. Hamilton TC, Young RC, McKoy WM, Grotzinger KR, Green JA, Chu EW, Whang-Peng J, Rogan AM, Green WR, Ozols RF: Characterization of a human ovarian carcinoma cell line (NIH:OVCAR-3) with androgen and estrogen receptors. Cancer Res 1983, 43:5379-5389.

38. Duyndam MC, Hilhorst MC, Schluper HM, Verheul HM, van Diest PJ, Kraal G, Pinedo HM, Boven E: Vascular endotherial growth factor-165 overexpression stimulates angiogenesis and induces cyst formation and macrophage infiltration in human ovarian cancer xenografts. Am J Pathol 2002, 160:537-548.

doi:10.1186/1756-0500-6-305

Cite this article as: Imura et al.: A novel angiomatoid epithelioid sarcoma cell line, Asra-EPS, forming tumors with large cysts containing hemorrhagic fluid in vivo. BMC Research Notes 2013 6:305. 